Research Paper

\title{
Vascular Hyperpermeability Response in Animals Systemically Exposed to Arsenic
}

\author{
Shih-Chieh Chen ${ }^{1,2,3 凶}$, Chao-Yuah Chang ${ }^{3}$, and Ming-Lu Lin ${ }^{4}$ \\ 1. Graduate Institute of Medicine, College of Medicine, Kaohsiung Medical University Kaohsiung, Taiwan \\ 2. Department of Medical Research, Kaohsiung Medical University Hospital, Kaohsiung, Taiwan \\ 3. Department of Anatomy, Faculty of Medicine, College of Medicine, Kaohsiung Medical University, Kaohsiung, Taiwan \\ 4. Department of Sports Medicine, Kaohsiung Medical University, Kaohsiung, Taiwan \\ $\triangle$ Corresponding author: Dr. Shih-Chieh Chen, Graduate Institute of Medicine, College of Medicine, Kaohsiung Medical University, 100 Shih-Chuan 1st Road, \\ Kaohsiung, Taiwan. Tel: 886-7-3121101 ext. 2301; Fax: 886-7-3119849; E-mail: jaychen@kmu.edu.tw \\ (C) Ivyspring International Publisher. This is an open access article distributed under the terms of the Creative Commons Attribution (CC BY-NC) license \\ (https://creativecommons.org/licenses/by-nc/4.0/). See http://ivyspring.com/terms for full terms and conditions.
}

Received: 2017.10.25; Accepted: 2018.01.05; Published: 2018.02.12

\begin{abstract}
The mechanisms underlying cardiovascular diseases induced by chronic exposure to arsenic remain unclarified. The objectives of this study were to investigate whether increased vascular leakage is induced by inflammatory mustard oil in mice systemically exposed to various doses of arsenic and whether an increased vascular leakage response is still present in arsenic-fed mice after arsenic discontinuation for 2 or 6 months. ICR mice were fed water or various doses of sodium arsenite $(10,15$, or $20 \mathrm{mg} / \mathrm{kg} /$ day; 5 days/week) for 8 weeks. In separate experiments, the mice were treated with sodium arsenite $(20 \mathrm{mg} / \mathrm{kg})$ for 2 or 8 weeks, followed by arsenic discontinuation for 2 or 6 months. Vascular permeability to inflammatory mustard oil was quantified using Evans blue (EB) techniques. Both arsenic-exposed and water-fed (control) mice displayed similar basal levels of EB leakage in the ears brushed with mineral oil, a vehicle of mustard oil. The levels of EB leakage induced by mustard oil in the arsenic groups fed with sodium arsenite $(10$ or $15 \mathrm{mg} / \mathrm{kg}$ ) were similar to those of water-fed mice. However, increased levels of EB leakage in response to mustard oil stimulation were significantly higher in mice treated with sodium arsenite $(20 \mathrm{mg} / \mathrm{kg}$; high dose) than in arsenic-fed (10 or $15 \mathrm{mg} / \mathrm{kg}$; low and middle doses) or control mice. After arsenic discontinuation for 2 or 6 months, mustard oil-induced vascular EB leakage in arsenic-fed $(20 \mathrm{mg} / \mathrm{kg})$ mice was similar to that in control mice. Dramatic increases in mustard oil-induced vascular leakage were only present in mice systemically exposed to the high arsenic dose, indicating the synergistic effects of the high arsenic dose and mustard oil.
\end{abstract}

Key words: Arsenic, sodium arsenite, vascular leakage, vascular hyperpermeability, mustard oil, vasoactive agents

\section{Introduction}

Arsenic is a ubiquitous metalloid present in the environment. Chronic arsenic exposure through contamination of drinking water is a global health issue [1]. Inorganic arsenical compounds such as arsenites (As $\left.{ }^{I I I}\right)$ and arsenates $\left(\mathrm{As}^{\mathrm{V}}\right)$ are typically found in drinking water contaminated with arsenic [1]. It is known that arsenic ingestion is associated with tumors of the urinary bladder, skin, and lung. Epidemiological research has shown that cardiovascular diseases, including stroke, atherosclerosis, and ischemic heart disease, are significantly increased in individuals chronically exposed to arsenic [2, 3]. Arsenic exposure via drinking water is also closely related to Blackfoot disease (BFD), a peripheral vascular disease, in Taiwan [4].

We have previously shown the impact of arsenic on vascular integrity via in situ exposure and systemic exposure by gavage feeding with observable and quantifiable tracer (Evans blue; EB) techniques [5-7]. Following in situ arsenic exposure via intradermal injection, animal skin microvessels exhibited a hyperpermeable or leaky response such that 
extravasated EB injected into the cardiovascular system was significantly increased [7, 8]. Previous studies have also indicated that mustard oil induced dramatic vascular leakage in mice systemically exposed to sodium arsenite at a dose of $20 \mathrm{mg} / \mathrm{kg}$ via gavage feeding for 2 months [6]. Recent time-course studies showed that, with a shorter period (2 weeks) of arsenic exposure to the same dose $(20 \mathrm{mg} / \mathrm{kg})$, arsenic-exposed mice displayed general vascular leakage responding to mustard oil challenge, similar to the response of water-fed (control) mice [9]. In the present study, we examined whether increased vascular hyperpermeability (leakage) was induced by mustard oil in experimental animals treated with various doses of arsenic. We also investigated whether the dramatic vascular leakage occurred in response to mustard oil in mice pretreated with sodium arsenite $(20 \mathrm{mg} / \mathrm{kg})$ and short- or long-term arsenic discontinuation.

\section{Materials and Methods}

\section{Systemic arsenic exposure in animals via oral gavage feeding}

Male (ICR) mice were purchased from BioLasco Co. (Taipei, Taiwan) and housed at the Kaohsiung Medical University animal center according to standard animal husbandry practice and regulations. Animal experiments of this study were approved by and conducted in accordance with the guidelines of the Institutional Animal Care and Usage Committee at Kaohsiung Medical University (IACUC Approval No. 92020 and 97103). Mice (average body weight, 30 g) had access to normal rodent chow and drinking water ad libitum. The inorganic sodium arsenite used in this study was trivalent arsenical arsenic (III), and the arsenic treatment consisted of sodium arsenite (2 $\mathrm{mg} / \mathrm{ml}$; Sigma-Aldrich, St. Louis, MO, USA) in Milli-Q water as described previously [9]. Four groups of animals were administered sodium arsenite (10, 15 , or $20 \mathrm{mg} / \mathrm{kg}$ body weight) via gavage 5 days/week or Milli-Q water only (control) for 8 weeks. Although gavage via forced oral feeding is not physiological compared with drinking water ad libitum, the actual doses of arsenic ingestion by gavage feeding are achievable in experimental animals. Both arsenic-fed and control mice were divided into different study groups (see below).

In separate experiments, the mice were treated with either sodium arsenite $(20 \mathrm{mg} / \mathrm{kg})$ or Milli-Q water (control) for 2 or 8 weeks followed by arsenic discontinuation of 2 or 6 months. During the experimental periods, the mice had access to normal rodent chow and drinking water ad libitum.

\section{Measurement of vascular permeability changes in ears}

The external ears of mice consist of a cartilage plate covered by thin skin layers with microvessels on both sides, and the vascular response can be shown on the ear skin when vasoactive stimuli are applied on the ear skin. Vascular permeability changes in mouse ears after disruption of the vascular endothelium were also demonstrated by significant increases in the extravasated EB dye injected into the circulation as described in previous studies [6,9]. Briefly, the mice were anesthetized with pentobarbital sodium (50 $\mathrm{mg} / \mathrm{kg}$, intraperitoneally) and administered EB (30 $\mathrm{mg} / \mathrm{kg}$ ) intravenously via the tail vein. Both surfaces of the right ears received $5 \mu \mathrm{l}$ of diluted mustard oil (allyl isothiocyanate in $10 \%$ in mineral oil; v/v) for 1 $h$, and the left ears were treated with mineral oil, which served as a control. At the end of the experiment, the mice were sacrificed, and the ears surgically removed. EB extravasation or vascular leakage in ear samples was extracted, quantified, and expressed as EB ( $\mu \mathrm{g}) /$ ear.

\section{Results}

\section{Association between increased vascular leakage and arsenic exposure dose}

To examine the long-term effect of various doses of arsenic on the vascular permeability of microvessels stimulated with mustard oil, the mice were fed with various doses of arsenic $(0,10,15$, or 20 $\mathrm{mg} / \mathrm{kg}$ ) for 8 weeks, and the vascular permeability in the mouse ears following the application of mustard oil was measured with EB. The levels of EB leakage induced by mineral oil were similar in all groups of mice regardless of the various arsenic doses or water (control) (Fig. 1). The levels of EB leakage in response to mustard oil stimulation in the arsenic groups fed both low and middle doses of sodium arsenite (10 or $15 \mathrm{mg} / \mathrm{kg}$ ) were similar to those in control mice (Fig. 1). However, increased levels of EB leakage induced by mustard oil were significantly higher in arsenic-fed mice $(20 \mathrm{mg} / \mathrm{kg}$; high dose) than in mice treated with lower arsenic doses (10 or $15 \mathrm{mg} / \mathrm{kg}$ ) or water. Throughout the experimental periods, all mice treated with middle and high doses of arsenic or water (control) grew normally with similar body weights (Fig. 2). The low arsenic dose $(10 \mathrm{mg} / \mathrm{kg})$ group also displayed body weight changes similar to those of mice fed higher doses of arsenic (data not shown).

\section{Vascular hyperpermeability response after arsenic discontinuation}

To examine whether an increased vascular hyperpermeability response was still present in 
arsenic-fed mice after discontinuation of arsenic exposure for a period of time, the mice received the high arsenic dose for 8 weeks followed by arsenic discontinuation for 6 months. Both arsenic-exposed and water-fed (control) mice displayed similar basal

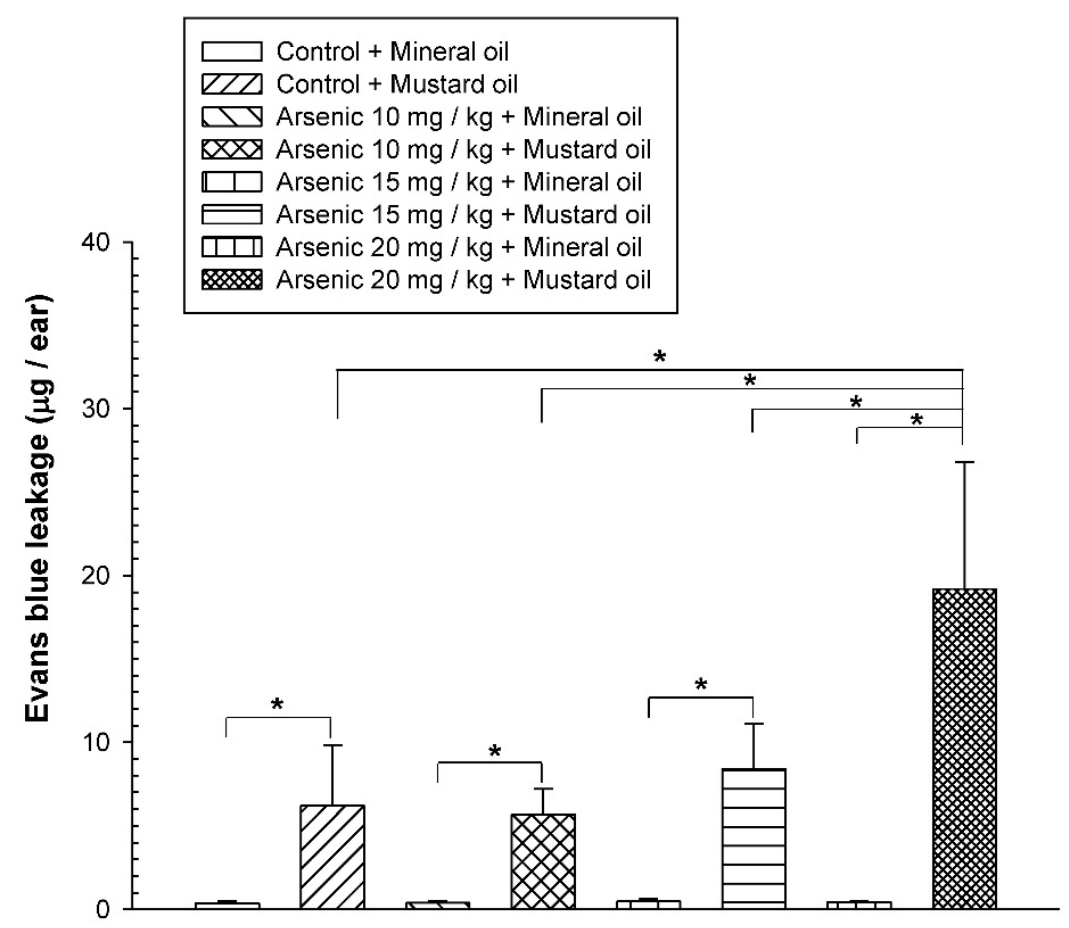

Fig. 1. Vascular leakage induced by mustard or mineral oil in ears. The animals were fed various doses $(10,15$, or $20 \mathrm{mg} / \mathrm{kg}$ ) of sodium arsenite (arsenic groups) or water (control) for 8 weeks. Anesthetized mice were intravenously injected with Evans blue (EB); the right ears were exposed to mustard oil, while the left ears were treated with mineral oil for $1 \mathrm{~h}$. At the end of the experiment, EB extravasation in ear samples was extracted, quantified, and expressed as the mean $\mathrm{EB}(\mu \mathrm{g}) / \mathrm{ear} \pm$ standard deviation (SD), $n=6$ /group. * indicates $p<0.05$.

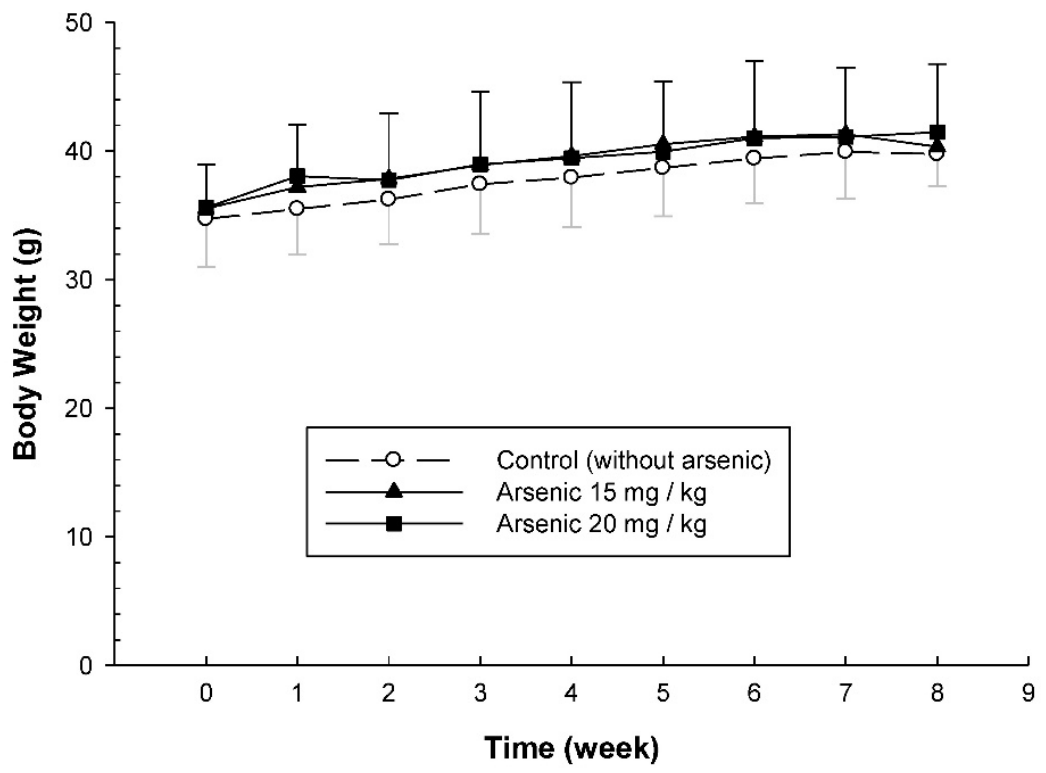

Fig. 2. Body weight changes of arsenic-fed mice. Animals were fed middle and high doses of sodium arsenite (arsenic group) or water (control) for 8 weeks as in Figure 1. The body weight of mice was shown on the $Y$-axis (mean $\pm S D ; n=8-12 /$ group). levels of EB leakage in the ears brushed with mineral oil (Fig. 3). After arsenic discontinuation for 6 months, mustard oil-induced EB leakage in arsenic-fed mice was still similar to that in the control (water) group (Fig. 3).

To examine whether the adverse consequences of increased vascular leakage may occur in response to mustard oil in arsenic-fed mice after discontinuing arsenic feeding for a short period of time, the mice received the high arsenic dose $(20 \mathrm{mg} / \mathrm{kg})$ for 2 weeks and arsenic discontinuation for 2 months. Both arsenic-exposed and water-fed (control) mice displayed similar basal levels of EB leakage in the ears brushed with mineral oil (Fig. 4). After arsenic discontinuation for 2 months, mustard oil-induced EB leakage in arsenic-fed mice was similar to that in the control (water) group (Fig. $4)$.

\section{Discussion}

Previous studies indicated that both the mean systolic and diastolic arterial pressures and body weights in mice fed a high arsenic dose $(20 \mathrm{mg} / \mathrm{kg})$ were not significantly different from those in control mice $[6,10]$. Our results showed that mice systemically exposed to various doses of arsenic were not significantly different from control mice in terms of growth and behavior, suggesting that arsenic doses of 10-20 $\mathrm{mg} / \mathrm{kg}$ body weight do not produce any undesirable physiological stress or overt toxicity in ICR mice.

Our data showed that all groups of arsenic-fed and control mice exhibited similar basal levels of EB leakage in ears brushed with mineral oil, indicating that the barrier integrity of the vascular endothelium was maintained in mice systemically exposed to arsenic for 2 months regardless of the various arsenic doses. Our data also demonstrated that EB leakage levels responding to mustard oil stimulation in the arsenic-exposure groups of the low and middle doses (sodium arsenite; 10 or $15 \mathrm{mg} / \mathrm{kg}$ ) were similar to those in water-fed (control) mice. However, increased levels of EB leakage induced by mustard oil were significantly higher 
in the high arsenic dose $(20 \mathrm{mg} / \mathrm{kg})$ group than in mice treated with lower arsenic doses (10 or 15 $\mathrm{mg} / \mathrm{kg}$ ) or water. These results suggest that the effective arsenic dose, $20 \mathrm{mg} / \mathrm{kg}$, is required for experimental animals to display increased vascular leakage in the presence of inflammatory mustard oil. Our previous studies demonstrated increased vascular EB leakage induced by mustard oil and histamine in mice systemically exposed to an identical arsenic dose [9]. Taken together, in response to vasoactive agents, the general or dramatic vascular leakage response in mice was related to low or high dose arsenic exposure, respectively. Multiple

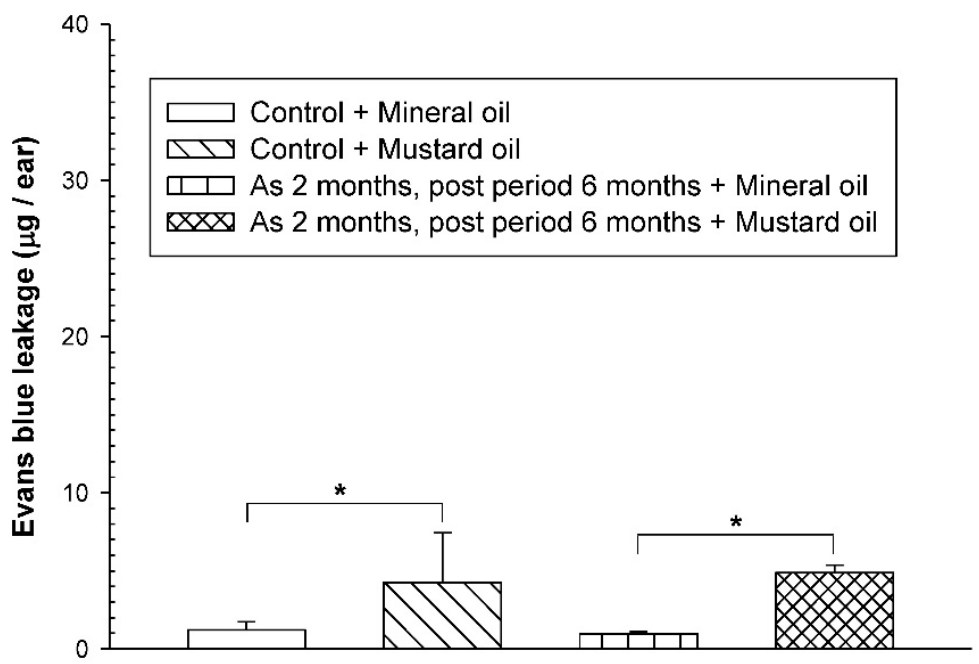

Fig. 3. Vascular leaky response in mice treated with a high arsenic dose for 2 months and arsenic discontinuation for 6 months. Animals $(n=4 /$ group) were treated with sodium arsenite $(20$ $\mathrm{mg} / \mathrm{kg}$; As) or water (control) for 8 weeks, and mice discontinued arsenic treatment for 6 months. Vascular permeability in the ears in response to mustard or mineral oil was measured with $\mathrm{EB}$ dye as in Figure 1.* indicates $p<0.05$.

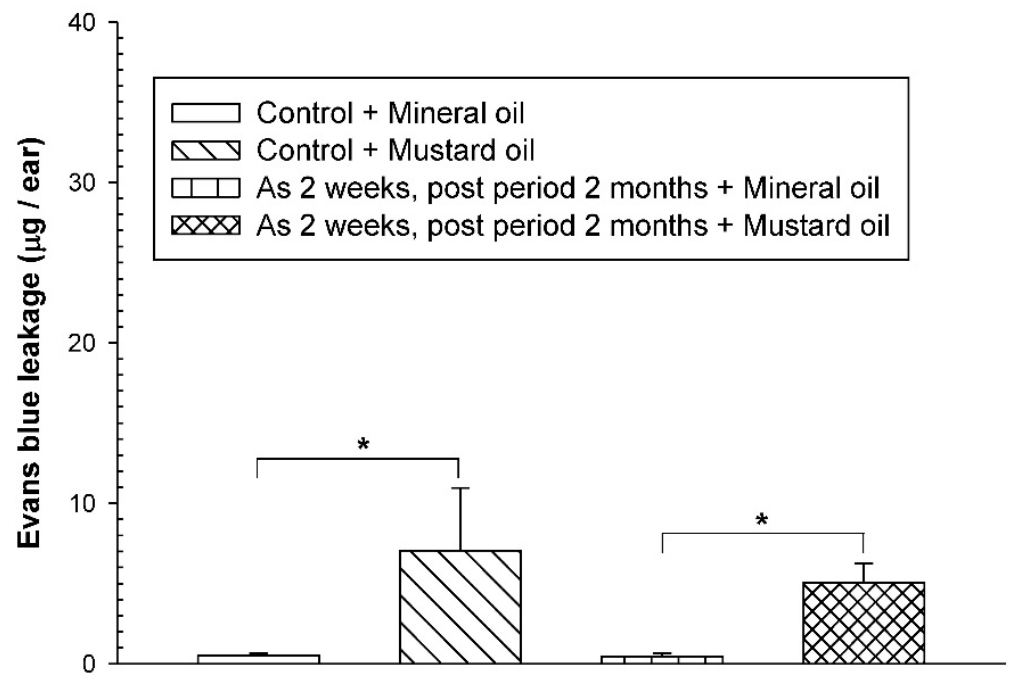

Fig. 4. Vascular leaky response in mice treated with arsenic for 2 weeks and arsenic discontinuation for 2 months. Animals ( $n=4 /$ group) were treated with sodium arsenite ( 20 $\mathrm{mg} / \mathrm{kg}$; As) or water (control) for 2 weeks, and mice discontinued arsenic treatment for 2 months. Vascular permeability in the ears in response to mustard or mineral oil was measured with $\mathrm{EB}$ dye as in Figure 1. * indicates $p<0.05$. mechanisms of the dysregulated contractile machinery and junctional barrier in endothelial cells have been attributed to a dramatic vascular leakage response in mice systemically exposed to arsenic [6, 9]. Oxidative injury of endothelial cells induced by arsenic exposure has been long suspected $[5,11]$.

Following arsenic exposure for 2 or 8 weeks and arsenic discontinuation for 2 or 6 months, the basal levels of EB leakage in arsenic-fed mice were similar to those in control mice, indicating that the barrier integrity of the vascular endothelium remained intact in arsenic-fed mice even after arsenic discontinuation for a period of time. Mustard oil-induced EB leakage in mice subjected to arsenic treatment and subsequent arsenic discontinuation were similar to those in control mice, indicating that dramatic vascular leakage induced by mustard oil was no longer present in arsenic-fed mice after arsenic discontinuation for a period of time. It is known that arsenic is rapidly excreted in urine [12]. Previous studies indicated that arsenic does not accumulate at the injection site after intradermal injection $[7,8]$. Taken together, these studies indicate that the effective arsenic dose exhibits a synergistic effect to enhance dramatic vascular leakage induced by mustard oil in mice systemically exposed to arsenic.

The co-presence of arsenic and other toxic substances has been shown in arsenicpoisoning areas. The people of Bangladesh are exposed to toxic metals such as antimony and lead in drinking water in addition to arsenic [13]. BFD is closely related to arsenic exposure via drinking water and is characterized by pathological alterations of the blood vessels from the inner endothelium to smooth muscle layers, leading to ulcerous and gangrenous tissue. Besides arsenic, other contaminants such as humic acid are present in the drinking water in arseniasis areas [14, 15]. Accordingly, genetically altered mice deficient in apolipoprotein $\mathrm{E}$ (ApoE) or low-density lipoprotein (LDL) receptor (LDLr) have been used to establish atherosclerosis disease models. The accelerated formation of atherosclerotic lesions was observed in ApoE-/- or LDLr knockout mice chronically exposed to arsenic $[16,17]$, suggesting that accelerated atherosclerotic lesions were a result of synergistic effects of arsenic and hyperlipidemia. It is known that the 
incidence rate of BFD is greatly reduced by implementation of a tap water system via avoiding arsenic-contaminated water [18]. Indeed, our results showed that dramatic vascular leakage induced by mustard oil was no longer present in arsenic-fed mice following arsenic discontinuation for a period of time. However, epidemiological studies indicated a significant increase in cardiovascular-related diseases in arseniasis areas, although residents had already discontinued the ingestion of arsenic-contaminated groundwater [19]. It is interesting to speculate that, in addition to arsenic, people in arseniasis areas still face other risk factors, such as hyperlipidemia, that are detrimental to the vascular system. Thus, further studies may be warranted to investigate potential risk factors that co-present with arsenic and their underlying interaction mechanisms.

In summary, mice treated with a high dose, but not a low dose, of arsenic exhibited dramatic vascular leakage as evidenced by greatly increased dye leakage induced by inflammatory mustard oil. Increased vascular leakage was no longer present in mice fed a high dose of arsenic followed by arsenic discontinuation for a period of time. Taken together, these studies indicate that vascular dysfunction shown as increased vascular leakage induced by mustard oil is the result of synergism of the high arsenic dose and vasoactive agents such as mustard oil.

\section{Acknowledgments}

This work was supported by grants from the National Science Council, Taiwan, R.O.C. (NSC 95-2320-B-037-030; NSC 98-2320-B-037-019-MY3). The authors thank Dr. Louis W Chang, retired from the National Health Research Institutes, Taiwan, for sharing his thoughtful insights regarding arsenic exposure and vascular diseases in this study. The authors also thank Ming-Hsien Tsai for performing animal studies of increased vascular leakage related to arsenic exposure doses when he was a graduate student at Kaohsiung Medical University, Kaohsiung, Taiwan.

\section{Competing Interests}

The authors have declared that no competing interest exists.

\section{References}

1. Naujokas MF, Anderson B, Ahsan H, Aposhian HV, Graziano JH, Thompson $\mathrm{C}$, et al. The broad scope of health effects from chronic arsenic exposure: update on a worldwide public health problem. Environ Health Perspect. 2013; 121: 295-302.

2. Balakumar P, Kaur J. Arsenic exposure and cardiovascular disorders: an overview. Cardiovasc Toxicol. 2009; 9: 169-76.

3. Thomas DJ, Styblo M, Lin S. The cellular metabolism and systemic toxicity of arsenic. Toxicol Appl Pharmacol. 2001; 176: 127-44.
4. Tseng WP. Effects and dose-response relationships of skin cancer and blackfoot disease with arsenic. Environ Health Perspect. 1977; 19: 109-19.

5. Chen SC, Chen WC. Vascular leakage induced by exposure to arsenic via increased production of NO, hydroxyl radical and peroxynitrite. Microvasc Res. 2008; 75: 373-80.

6. Chen SC, Liu CC, Huang SY, Chiou SJ. Vascular hyperpermeability in response to inflammatory mustard oil is mediated by Rho kinase in mice systemically exposed to arsenic. Microvasc Res. 2011; 82: 182-9.

7. Chen SC, Tsai MH, Wang HJ, Yu HS, Chang LW. Vascular permeability alterations induced by arsenic. Hum Exp Toxicol. 2004; 23: 1-7.

8. Tsai MH, Chen SC, Wang HJ, Yu HS, Chang LW. A mouse model for the study of vascular permeability changes induced by arsenic. Toxicol Mech Methods. 2005; 15: 433-7.

9. Chen SC, Huang SY, Lu CY, Hsu YH, Wang DC. Microvascular dysfunction with increased vascular leakage response in mice systemically exposed to arsenic. Cardiovasc Toxicol. 2014; 14: 222-31.

10. Chen SC, Huang SY, Lin WT, Yang RC, Yu HS. Aortic smooth muscle cell alterations in mice systemically exposed to arsenic. Heart Vessels. 2016; 31: 807-15.

11. Gurr JR, Yih LH, Samikkannu T, Bau DT, Lin SY, Jan KY. Nitric oxide production by arsenite. Mutat Res. 2003; 533: 173-82.

12. Smith AH, Lingas EO, Rahman M. Contamination of drinking-water by arsenic in Bangladesh: a public health emergency. Bull World Health Organ. 2000; 78: 1093-103.

13. Frisbie SH, Ortega R, Maynard DM, Sarkar B. The concentrations of arsenic and other toxic elements in Bangladesh's drinking water. Environ Health Perspect. 2002; 110: 1147-53.

14. Lu FJ. Blackfoot disease: arsenic or humic acid? Lancet. 1990; 336: 115-6.

15. Yu HS, Sheu HM, Ko SS, Chiang LC, Chien CH, Lin SM, et al. Studies on blackfoot disease and chronic arsenism in southern Taiwan: with special reference to skin lesions and fluorescent substances. J Dermatol. 1984; 11: 361-70.

16. Bunderson M, Brooks DM, Walker DL, Rosenfeld ME, Coffin JD, Beall HD. Arsenic exposure exacerbates atherosclerotic plaque formation and increases nitrotyrosine and leukotriene biosynthesis. Toxicol Appl Pharmacol. 2004; 201: 32-9.

17. Simeonova PP, Hulderman T, Harki D, Luster MI. Arsenic exposure accelerates atherogenesis in apolipoprotein E(-/-) mice. Environ Health Perspect. 2003; 111: 1744-8.

18. Tseng $\mathrm{CH}$. Blackfoot disease and arsenic: a never-ending story. J Environ Sci Health C Environ Carcinog Ecotoxicol Rev. 2005; 23: 55-74.

19. Wang SL, Chiou JM, Chen CJ, Tseng CH, Chou WL, Wang CC, et al. Prevalence of non-insulin-dependent diabetes mellitus and related vascular diseases in southwestern arseniasis-endemic and nonendemic areas in Taiwan. Environ Health Perspect. 2003; 111: 155-59. 